Supplementary Data

\title{
Multifunctional Silica-Silicone Nanocomposite with Regenerative Superhydrophobic Capabilities
}

\author{
Assem Elzaabalawy, Pieter Verberne, Shaker A. Meguid* \\ Mechanics and Aerospace Design Lab, University of Toronto, Toronto M5S 3G8, Canada
}

*Corresponding author

Shaker A. Meguid

Tel.: +1 (416) 978 5741; Fax: +1 (416) 9787753.

E-mail address: meguid@mie.utoronto.ca 


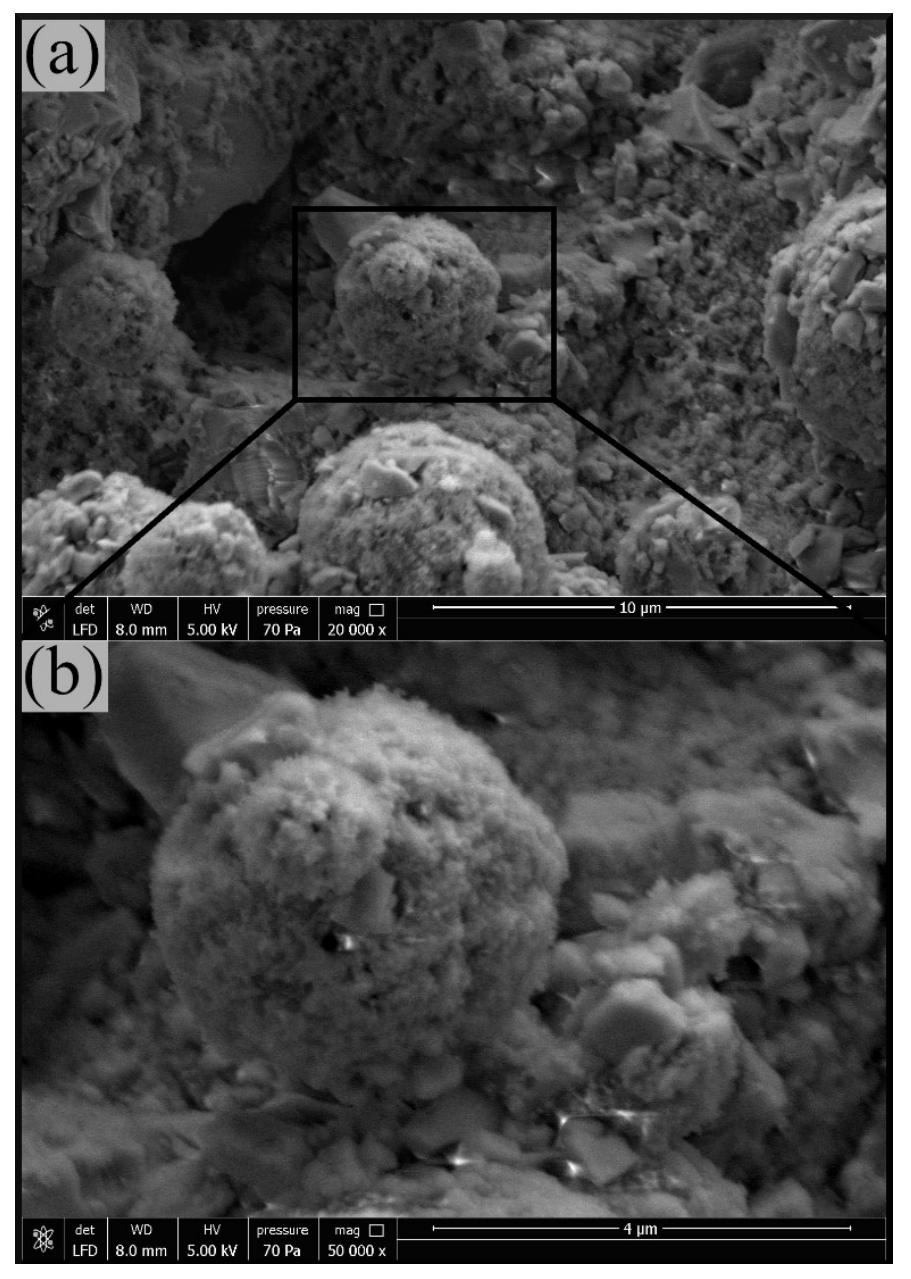

Figure S1. SEM images for spray coated samples with $14 \mathrm{wt} \%$ silica at (a) 20,000x and (b) 50,000x magnification. 
(a)

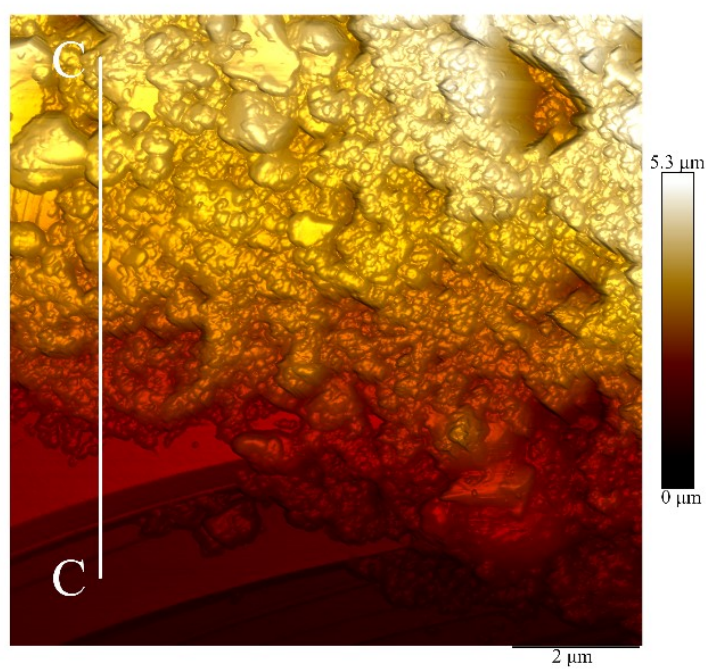

(b)

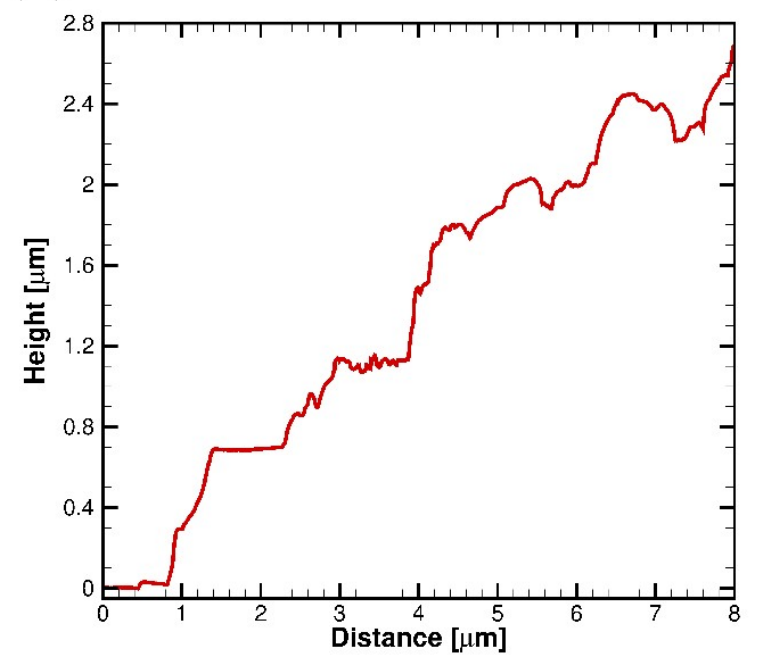

Figure S2. AFM images for a spray-coated surface with 14 wt $\%$ silica (a) surface height map (b) height profile through section $\mathrm{C}-\mathrm{C}$. 


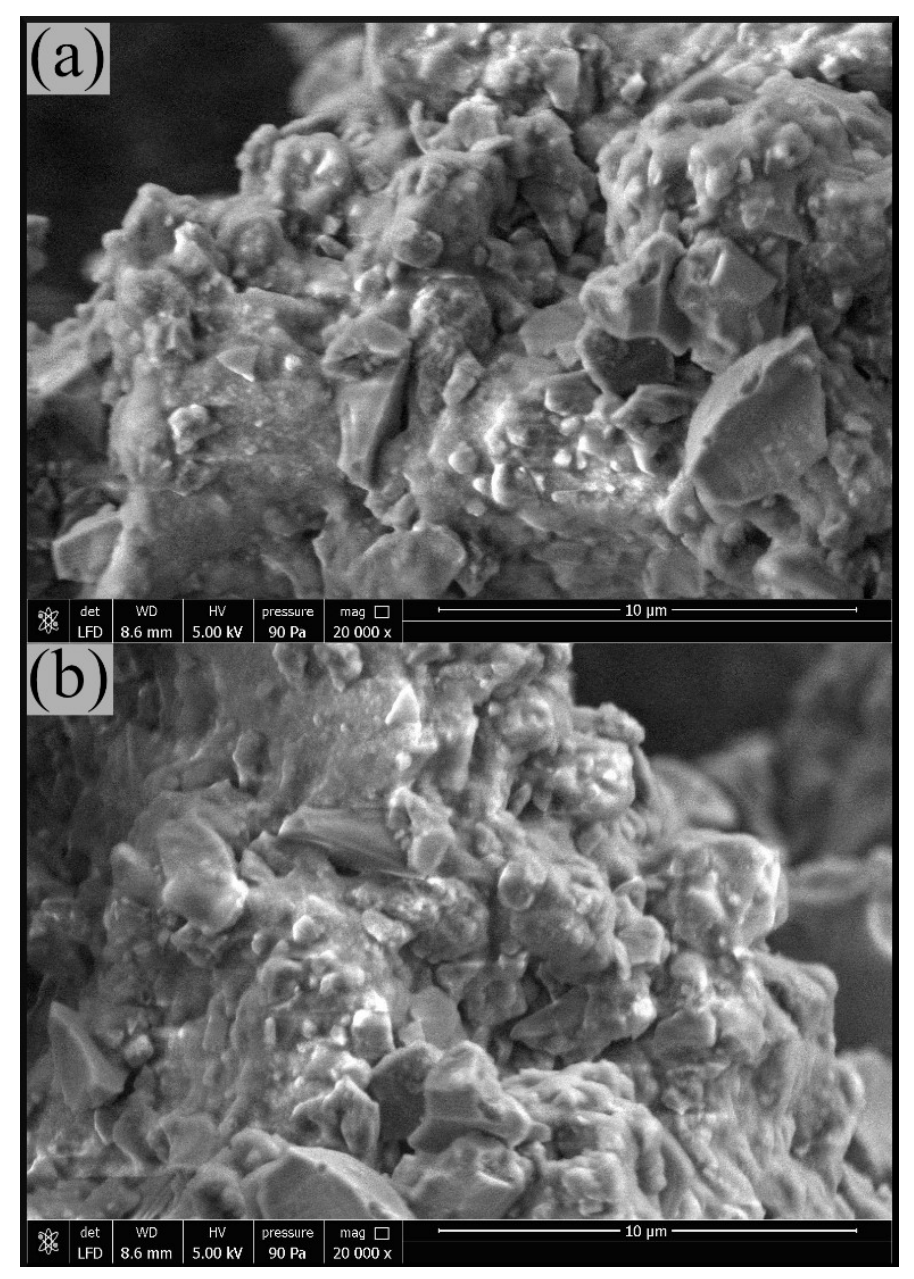

Figure S3. SEM images for nanocomposite monoliths with $9 \mathrm{wt} \%$ silica at 20,000x for (a) scanned location \#1 (b) scanned location \#2. 